\title{
Association of antiepileptic drug usage, trace elements and thyroid hormone status
}

\author{
Chantal Zevenbergen ${ }^{1,2, *}$, Tim I M Korevaar ${ }^{1,2, *}$, Andrea Schuette ${ }^{3, *}$, \\ Robin P Peeters ${ }^{1,2}$, Marco Medici ${ }^{1,2}$, Theo J Visser ${ }^{1,2}$, Lutz Schomburg ${ }^{3}$ \\ and W Edward Visser ${ }^{1,2}$ \\ ${ }^{1}$ Department of Internal Medicine and ${ }^{2}$ Rotterdam Thyroid Center, Erasmus Medical Center, Wytemaweg 80, 3015 \\ CN Rotterdam, The Netherlands and ${ }^{3}$ Institut für Experimentelle Endokrinologie, Charité-Universitätsmedizin \\ Berlin, Augustenburger Platz 1, D-13353 Berlin, Germany \\ *(C Zevenbergen, T I M Korevaar, A Schuette contributed equally to this work)
}

Correspondence

should be addressed

to W E Visser

Email

w.e.visser@erasmusmc.nl

\begin{abstract}
Background: Levels of thyroid hormone (TH) and trace elements (copper ( $\mathrm{Cu}$ ) and selenium (Se)) are important for development and function of the brain. Anti-epileptic drugs (AEDs) can influence serum TH and trace element levels. As the relationship between AEDs, THs, and trace elements has not yet been studied directly, we explored these interactions. Method: In total 898 participants, from the Thyroid Origin of Psychomotor Retardation study designed to investigate thyroid parameters in subjects with intellectual disability (ID), had data available on serum $\mathrm{Se}, \mathrm{Cu}$, thyroid stimulating hormone (TSH), free thyroxine $\left(\mathrm{FT}_{4}\right)$, tri-iodothyronine $\left(T_{3}\right)$, reverse $T_{3}, T_{4}$, and thyroxine-binding globulin (TBG); 401 subjects were on AED treatment. Differences in trace elements according to medication usage was investigated using ANOVA, and associations between trace elements and thyroid parameters were analysed using (non-) linear regression models. Results: Study participants were not deficient in any of the trace elements analyzed. AED (carbamazepine, valproate and phenytoin) usage was negatively associated with serum Se and showed compound-specific associations with Cu levels. After correction for drug usage, Se was positively associated with TSH levels, negatively associated with $\mathrm{FT}_{4}$ levels, and positively with $T_{3}$ levels. Cu was positively associated with $T_{4}, T_{3}$, and $r T_{3}$, which was largely dependent on TBG levels. Conclusion: The subjects with ID did not display profound deficiencies in trace element levels. AEDs were associated with serum Se and Cu levels, while serum Se and Cu were also associated with thyroid parameters. Further studies on the underlying mechanisms and potential clinical importance are warranted.
\end{abstract}

\section{Introduction}

Thyroid hormone (TH) is important for the normal development and energy metabolism of almost all tissues (1). The thyroid gland pre-dominantly secretes the inactive pro-hormone thyroxine $\left(\mathrm{T}_{4}\right)$, which is locally converted to the active form tri-iodothyronine $\left(T_{3}\right)$ by selenium (Se)-dependent enzymes of the family of iodothyronine deiodinases (2). $\mathrm{T}_{3}$ mediates its major effects by binding to nuclear TH receptors (TRs) which regulate the transcription of target genes (3). Abnormalities in TH status are commonly found among endocrine disorders (4) at varying prevalences according to the group of patients that is being studied $(5,6)$.

Essential trace elements, like Se and copper $(\mathrm{Cu})$, are micronutrients that are present in low concentrations in the human body and are dependent on a sufficiently high dietary intake. Trace elements are essential for many enzymatic reactions and are therefore important for proper functioning of biochemical pathways and the endocrine system (7).

Published by Bioscientifica Ltd. 
Sufficient levels of both TH and trace elements are important for normal development of the brain (8). Abnormalities in TH signaling can give rise to neurocognitive impairment, as illustrated by subjects with mutations in the gene encoding the $\mathrm{TH}$ transporter monocarboxylate transporter $8(M C T 8)(9,10)$ or in the TR THRA (encoding TR $\alpha)(11,12,13,14)$. Adequate levels of $\mathrm{Cu}$ are also important for normal development of the brain, as $\mathrm{Cu}$ is important in energy metabolism, antioxidative defense, and the production of neurotransmitters (15). Also, it was shown that $\mathrm{TH}$ or $\mathrm{Cu}$ deficiencies resulted in similar defects during rodent cerebral cortical development (16). The brain appears to preserve Se levels during Se shortage, as rats on a Se deficient diet did not display any neurological symptoms, because of only slightly reduced brain Se levels (17). However, mice lacking selenoprotein P (SelP), which is an important Se carrier, showed very low brain Se levels together with movement disorders and occasional seizures (18).

Only limited data on the relationship between TH and Se and $\mathrm{Cu}$ are currently available. It was shown in rats that adequate Se in nutrition supports $\mathrm{TH}$ synthesis and metabolism and protects the thyroid gland from damage by excessive exposure to reactive chemicals (19). Furthermore, in humans, high levels of $\mathrm{Cu}$ were associated with higher levels of both $\mathrm{T}_{3}$ and $\mathrm{T}_{4}$ (20). As a corollary, Bastian et al. $(16,21,22)$ showed in different rat studies that fetal deficiency of $\mathrm{Cu}$ resulted in impaired TH-regulated brain gene expression. While these studies suggested an interaction of the trace elements Se and $\mathrm{Cu}$ and $\mathrm{TH}$ during brain development, its relevance for humans is unknown.

In the Thyroid Origin of Psychomotor Retardation (TOP-R) study, thyroid parameters of subjects with intellectual disability (ID) were extensively profiled (23). In this cohort, it has been shown that $\mathrm{TH}$ profiles in subjects without anti-epileptic drugs (AEDs) were comparable with the general population. However, AEDs were strongly associated with decreased $\mathrm{T}_{4}$, free $\mathrm{T}_{4}\left(\mathrm{FT}_{4}\right), \mathrm{T}_{3}$, and $\mathrm{rT}_{3}$ levels which is in agreement with other studies $(24,25,26)$. It has been speculated that the changed thyroid parameters in patients that use AEDs can be explained by an influence of AEDs on binding proteins (27), a stimulation of hepatic degradation or conjugation of TH (28) or an altered peripheral deiodinase activity (23). Interestingly, AEDs have been associated with changes in serum levels of Se and $\mathrm{Cu}(23,29,30,31,32,33)$. However, the complex relationship between AEDs, THs, Se, and $\mathrm{Cu}$ has never been directly studied.
The aim of this study was to analyze the associations between AEDs, Se, $\mathrm{Cu}$, and thyroid parameters using the TOP-R cohort.

\section{Subjects and methods}

\section{TOP-R study}

The TOP-R study is a nation-wide cohort study in The Netherlands, which was designed to investigate thyroid parameters in subjects with intellectual disability (ID). The study population has been described in detail before (23). In short, subjects were excluded if the aetiology of the ID was known. Information about other medication was unavailable. Mean age was $47.9 \pm 0.5$ years, and $47 \%$ were women. The study was approved by the medical ethics committee of the Erasmus University Medical Centre. Written informed consent was obtained from the legally authorized representatives. Of the 946 eligible individuals, data on $\mathrm{TH}$ and trace element serum levels were available in 898 subjects, and information about thyroid medication (anti-thyroid drugs and $\mathrm{L}_{\mathrm{T}} \mathrm{T}_{4}$ replacement therapy) was available in 806 subjects and about AEDs in 786 subjects. Full case analyses according to this data did not change the results (data not shown). After exclusion of subjects that used thyroid-interfering medication $(n=40)$ and/or thyroid peroxidase antibodies (TPOAb) positive individuals (cut-off $>60 \mathrm{IU} / \mathrm{ml} ; n=24$ ), 834 subjects were included in one or more analyses. After exclusion, 372 of 725 eligible patients used AEDs (51.3\%).

\section{Measurements of thyroid status, Se, and $\mathrm{Cu}$}

Serum samples were stored frozen at $-20{ }^{\circ} \mathrm{C}$. Serum $\mathrm{T}_{4}$, $\mathrm{FT}_{4}$, and thyroid-stimulating hormone (TSH) were measured by chemiluminescence assays (Vitros ECI Immunodiagnostic System; Ortho-Clinical Diagnostics, Inc., Rochester, NY, USA). $\mathrm{T}_{3}$ was measured using an in-house RIA and $\mathrm{rT}_{3}$ using a commercial RIA (Immunodiagnostic Systems, Scottsdale, AZ, USA). Thyroxinebinding globulin (TBG) and TPO antibodies were determined by immunoassay (Immulite 2000, Siemens, Breda, The Netherlands). Se and $\mathrm{Cu}$ concentrations were determined by total reflection X-ray fluorescence spectroscopy (34). The method was validated with a Seronorm standard (Sero AS, Billingstad, Norway). Briefly, all samples were diluted 1:1 in a gallium-containing solvent for standardization. The analysis was performed in duplicate, and the results of each sample differed by $<20 \%$ for both Se and Cu. In every measurement run, 
a human control serum was included, allowing the calculation of an intra-assay coefficient of variation of $7 \%(\mathrm{Se})$ and $8 \%(\mathrm{Cu})$ and an inter-assay coefficient of variation of $12 \%(\mathrm{Se})$ and $18 \%(\mathrm{Cu})$ respectively.

\section{Statistical analysis}

To satisfy model assumptions, TSH levels were logarithmically transformed. The association between trace elements and thyroid parameters was investigated using ordinary least squares linear regression models with restricted cubic splines utilizing three to five knots. Figures show backtransformed axis values for TSH, and all associations were adjusted for sex, age, and relevant medication usage (covariates set to mean levels or most appearing category). The analyses were adjusted for medication usage when a drug was associated with a thyroid function parameter in a backward linear regression analysis, utilizing a cut-off of $P<0.15$. In addition, a variable for missing data on AED usage was added but did not reach the threshold for any thyroid parameters.

We investigated differences in the ratio of $\mathrm{T}_{3}$ to $\mathrm{rT}_{3}$ using linear regression analyses with a product term of the independent thyroid function parameter and trace element. Subsequently, to allow for non-linear associations/interactions, a sensitivity analysis was performed by adding quadratic terms and/or a product term of the trace element or thyroid function variables; these were maintained according to $P$ values or changes in $\mathrm{R}^{2}$. Interaction figures show the associations between thyroid function parameters according to low (red line with 95\% CI) or high (blue line with 95\% CI) trace element values (rounded number of 10 th percentile or 90th percentile respectively).

All statistical analyses were performed using R Statistical Software v 3.03 (1) (package rms or visreg) or SPSS version 21.0 for Windows.

\section{Results}

Descriptive statistics of the study population are shown in Supplementary Table 1, see section on supplementary data given at the end of this article. First, we studied the association between AED usage and serum Se and $\mathrm{Cu}$ levels (Fig. 1).

None of the study participants were deficient in Se or $\mathrm{Cu}$, whether they were on AED treatment or not. Carbamazepine or valproate usage was associated with lower serum Se levels (Fig. 1A and B). Usage of carbamazepine or phenytoin was associated with higher serum $\mathrm{Cu}$ levels and valproate usage with lower serum $\mathrm{Cu}$ levels
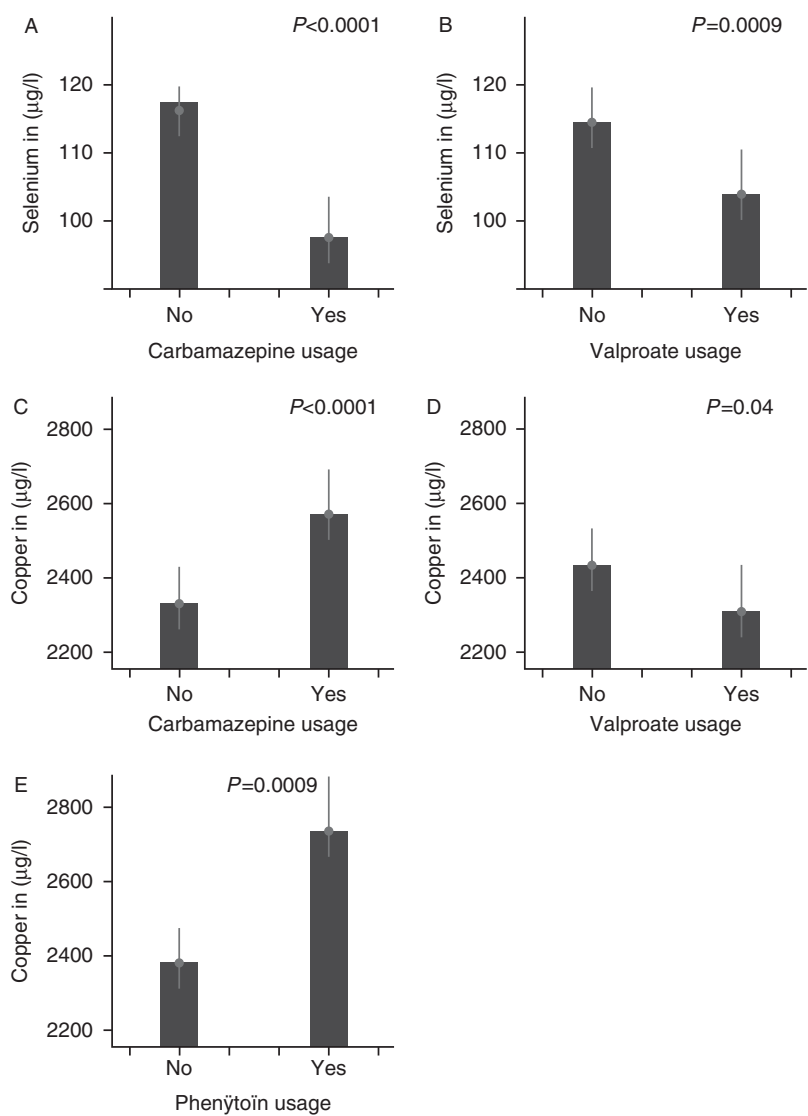

\section{Figure 1}

The association between AED usage and serum Se or $\mathrm{Cu}$ and as predicted mean (gray dot) and $95 \% \mathrm{Cl}$ (gray line). In addition, there was no dose-dependent effect of AED usage for $A, B, C, D$ and $\mathrm{E}(P=0.16 ; P=0.32 ; P=0.57 ; P=0.40 ;$ and $P=0.62$ respectively). All analyses were performed in subjects with AED usage data available after exclusion of subjects with thyroid medication usage or TPOAb positivity and were adjusted for sex and age.

(Fig. 1C, D and E). Other AED usage was not associated with serum Se or $\mathrm{Cu}$ levels, and there was no association between the daily dosage of AEDs and $\mathrm{Se}, \mathrm{Cu}$, or TH levels (data not shown). Thus, commonly prescribed AEDs affect serum Se and $\mathrm{Cu}$ levels in a compound-specific way.

Next, we studied associations between serum Se and $\mathrm{Cu}$ levels and thyroid parameters. The associations between serum Se levels and thyroid parameters are shown in Fig. 2. After correction for drug usage, Se was positively associated with TSH levels ( $\beta \pm$ s.E.M; $0.0008 \pm$ 0.0003; $P=0.03)$, negatively associated with $\mathrm{FT}_{4}$ levels (linearly for Se below 125: $-0.0212 \pm 0.0065 ; P=0.001$ ), and positively with $\mathrm{T}_{3}$ levels (linearly for Se below 125: 

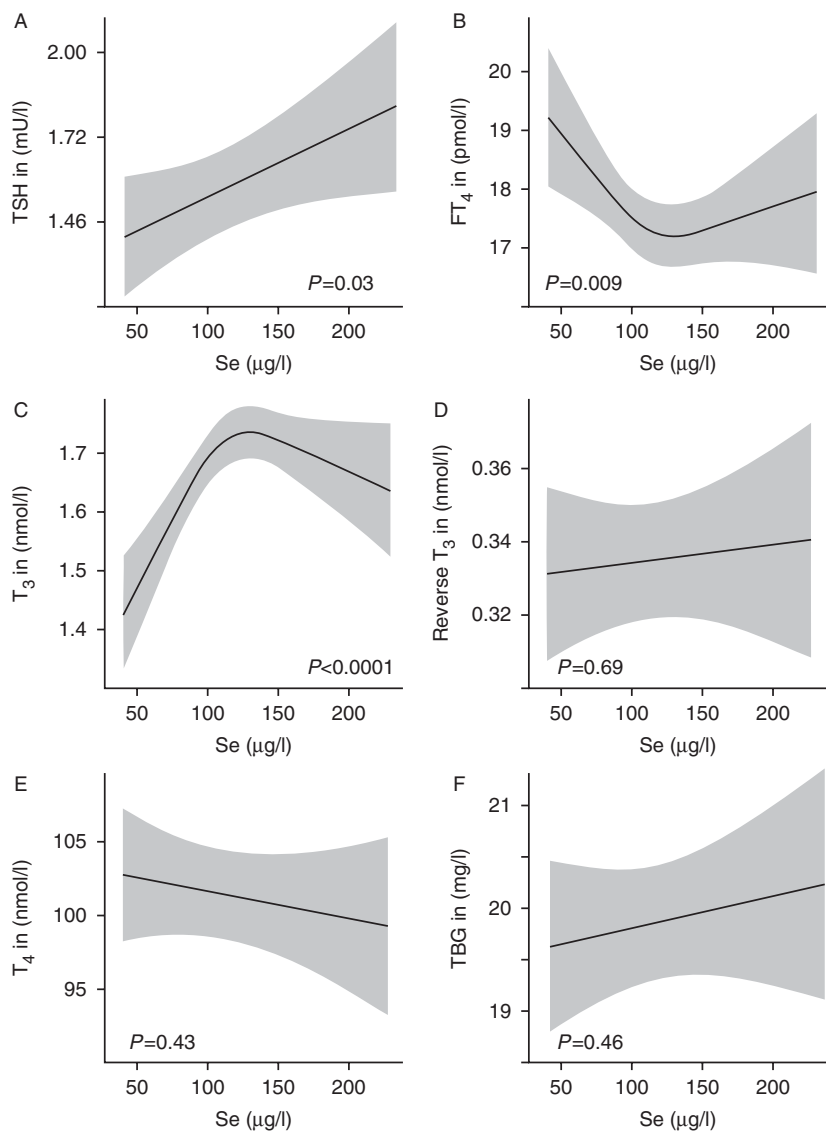

Figure 2

Graphs show the association between serum selenium and thyroid function parameters, as predicted mean (black line) and $95 \% \mathrm{Cl}$ (grey area). All analyses were performed after exclusion of subjects with thyroid medication usage or TPOAb positivity and were adjusted for sex, age, and antiepileptic drug usage and TBG levels.

$0.0028 \pm 0.0005 ; P<0.001 ;$ Fig. $2 \mathrm{~B}$ and $\mathrm{C})$. Since all three deiodinases are selenoproteins, we also investigated possible effects of trace elements on peripheral deiodinase activity. As a proxy for peripheral TH deiodination, we studied the association between serum $\mathrm{Se}, \mathrm{Cu}$, and $\mathrm{T}_{3} / \mathrm{rT}_{3}$ ratio. Serum Se was positively associated with the $\mathrm{T}_{3} / \mathrm{rT}_{3}$ ratio $(0.0122 \pm 0.0036 ; P<0.001$; Supplementary Figure $1 \mathrm{~A}$, see section on supplementary data given at the end of this article).

Next, the associations between serum $\mathrm{Cu}$ levels and thyroid parameters were studied. $\mathrm{Cu}$ levels were positively associated with $\mathrm{T}_{3}, \mathrm{rT}_{3}$, and $\mathrm{T}_{4}$ levels (Fig. 3A, B and $\mathrm{C}$ ). Also, a particularly strong association was observed between $\mathrm{Cu}$ and TBG (0.0022 $\pm 0.0002 ; P<0.001$; Fig. 3F). As estrogens may influence TBG levels, we also investigated sex differences. The association between $\mathrm{Cu}$ and TBG was stronger amongst women, as compared to men $(P$ interaction $=0.0007$; Supplementary Figure 2, see section on supplementary data given at the end of this article). After correction for TBG, the positive associations between serum $\mathrm{Cu}$ and $\mathrm{T}_{3}, \mathrm{rT}_{3}$, and $\mathrm{T}_{4}$ levels disappeared (Supplementary Figure 3). Serum Cu levels were not associated with changes in the $\mathrm{T}_{3} / \mathrm{rT}_{3}$ ratio (Supplementary Figure 1B).

\section{Discussion}

$\mathrm{TH}$ and the trace elements Se and $\mathrm{Cu}$ are important for normal neurocognitive development, and abnormal brain development may increase AED usage. The relationship
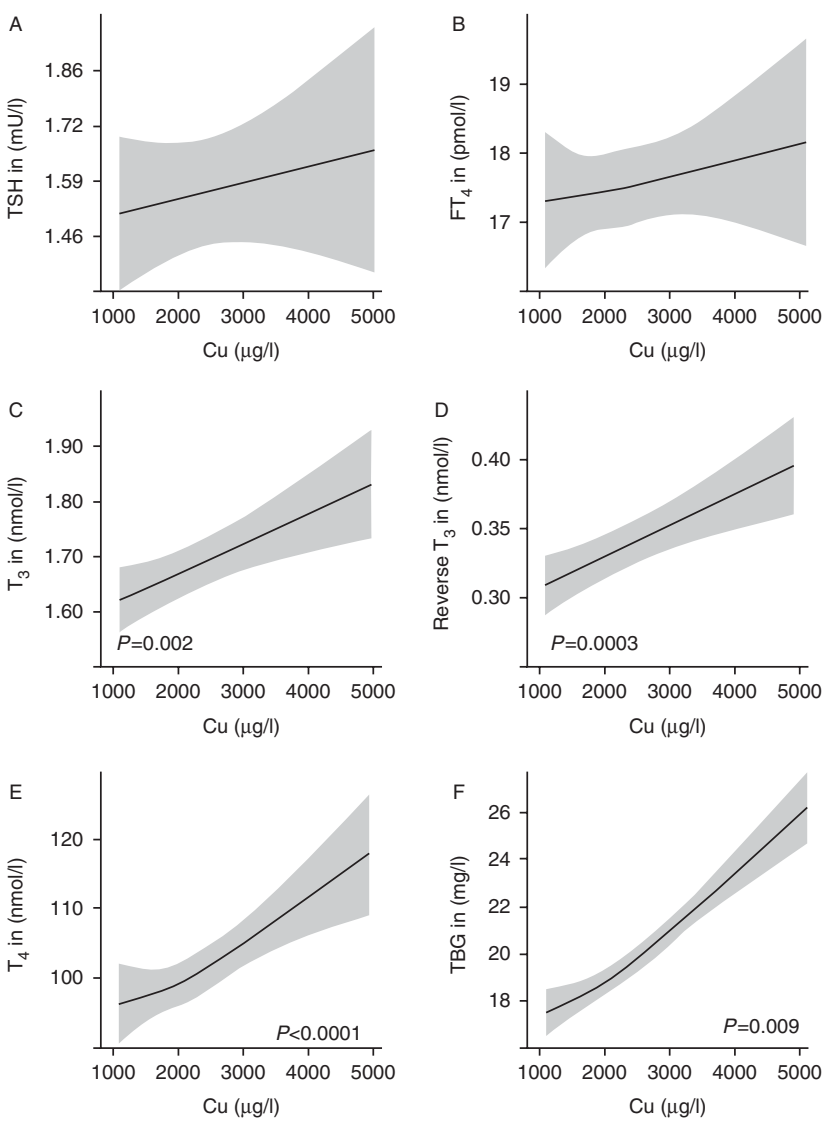

Figure 3

Graphs show the association between serum $\mathrm{Cu}$ and thyroid function parameters, as predicted mean (black line) and $95 \% \mathrm{Cl}$ (grey area). All analyses were performed after exclusion of subjects with thyroid medication usage or TPOAb positivity and were adjusted for sex, age, and antiepileptic drug usage, but not for TBG levels. 
between $\mathrm{TH}, \mathrm{Se}, \mathrm{Cu}$, and AED is currently unclear. In this study, we analyzed this relationship in the TOP-R cohort, in which $\mathrm{Se}$ and $\mathrm{Cu}$ and thyroid parameters were determined. Our analyses indicated that serum Se levels were associated with $\mathrm{TSH}, \mathrm{FT}_{4}$, and $\mathrm{T}_{3}$ levels, while serum $\mathrm{Cu}$ levels were associated with $\mathrm{T}_{3}, \mathrm{rT}_{3}$, and $\mathrm{T}_{4}$, via changes in TBG levels.

In this cohort of patients with ID, Se levels were significantly lower in patients that use valproate or carbamazepine, whereas phenytoin and carbamazepine usage was associated with increased $\mathrm{Cu}$ levels (Fig. 1). Unfortunately, these measurements were performed during treatment with AEDs; therefore, no data is available on pre- or post-treatment levels. Many studies described the effects of AEDs on trace element levels like Se and $\mathrm{Cu}$, although the effects of different classes of AEDs were neither consistent in magnitude nor in direction $(29,30$, $31,32,35,36,37)$. There are several potential reasons for these inconsistencies, ranging from dosage and duration of AED usage, age, health, and nutritional status of the patients to baseline trace element concentrations which differ profoundly in different geographical areas as well as the small number of subjects studied (38). Due to the observational nature of this study, it is very difficult to draw any conclusions on the causative or mechanistic features of these results. It is very well possible, although speculative, that AEDs interfere with the transport, metabolism, or excretion of trace elements, as is described for TH $(23,24,25,26,27,28)$. Furthermore, although the generalizability of our findings may be limited, it is important to be aware of confounders if Se or $\mathrm{Cu}$ levels are analyzed in subjects on commonly prescribed AEDs. Depending on the baseline level of the population, this may cause a physiologically meaningful disbalance.

Se is a trace element that is incorporated in selenocysteine, which is required for the normal production of selenoproteins $(39,40,41)$. In the last decades, accumulating evidence has shown that Se plays an essential role in $\mathrm{TH}$ biosynthesis and metabolism as well as in normal thyroid function $(42,43)$. The thyroid gland contains the highest Se concentration among human tissues due to the expression of several selenoproteins that are important in the maintainance of normal TH metabolism (deiodinases) and the protection of thyroid cells against oxidative damage such as glutathione peroxidases $(43,44)$. If Se is limiting, lower levels of selenoproteins are synthesized which may potentially disturb peroxide-dependent iodination of thyroglobulin in the thyroid, thyrocyte defence systems, and TH activation and inactivation $(19,41,45)$. In this study, we showed that serum Se was positively associated with $\mathrm{TSH}$, inversely associated with $\mathrm{FT}_{4}$, and positively associated with $T_{3}$ levels and the $T_{3} / r T_{3}$ ratio, as a proxy for peripheral deiodination (Fig. 2 and Supplementary Figure 1). This is also reminiscent of the constellation of critical illness, where a Se deficit often parallels a low $T_{3}$ syndrome. These results are in line with several studies in rats, in which Se deficiency decreased liver and kidney D1 activities in combination with modest alterations in thyroid parameters (increased $\mathrm{T}_{4}$ and decreased $\mathrm{T}_{3}$ levels) $(46,47,48,49,50)$. However, the majority of studies with human subjects on the interaction of Se and $\mathrm{TH}$ yielded inconsistent results (51). Our results indicated that even low normal Se levels may already impact negatively on the TH state. However, net effects of limiting Se availability for the expression of the three deiodinase isoenzymes in different human tissues are difficult to predict, as hierarchical principles control the expression of the selenoenzymes with organ-specific preferences (52).

$\mathrm{Cu}$ is necessary in many metabolic processes and plays an important role in endogenous anti-oxidative defense mechanisms (53). Studies of Bastian et al. $(16,21,22)$ in mice showed that low levels of $\mathrm{Cu}$ were associated with a decreased TH state, which interfered with normal brain development. Similarly, serum ceruloplasmin and $\mathrm{Cu}$ levels have recently been proposed as direct biomarkers of TH signaling (54). In line with these studies, we observed strong positive associations between serum $\mathrm{Cu}$ and $\mathrm{T}_{3}, \mathrm{rT}_{3}$, and $\mathrm{T}_{4}$ levels (Fig. 3). However, we were first to describe that these effects are totally driven by TBG (Supplementary Figure 3). Indeed, $\mathrm{FT}_{4}$ levels are not affected by $\mathrm{Cu}$ state. After correction for TBG, TH parameters were not significantly associated with serum $\mathrm{Cu}$ anymore, suggesting that the effects of $\mathrm{Cu}$ on thyroid function are mediated via changes in TBG. This may be explained by the fact that $\mathrm{Cu}$ may directly affect hepatic TBG expression, secretion, or turnover. TBG is the main transport protein for $\mathrm{TH}$ in serum, and many substances are known to influence TBG concentrations, such as estrogens, androgens, glucocorticoids, and heroin $(55,56)$. Most extensively studied are estrogens, which increased TBG levels by slowing its clearance via the liver, therefore increasing its half-life (55). In addition, estrogens have also been shown to increase serum $\mathrm{Cu}$ levels, which are most likely driven by an increase in ceruloplasmin, the transport protein of $\mathrm{Cu}(57,58,59$, $60,61)$. The association of $\mathrm{Cu}$ with TBG was stronger in women, which is consistent with a positive effect of $\mathrm{Cu}$ on TBG levels via estrogens, although this did not fully explain our observations. 
Our study has strengths and limitations. The strength of this study is that the TOP-R cohort contains one of the largest numbers of subjects with available data on serum $\mathrm{Se}, \mathrm{Cu}$, extensive profiling of $\mathrm{TH}$ parameters, and commonly prescribed AEDs. It is important to note that the generalizability of this study is limited, as the patients in the cohort are all diagnosed with unexplained ID. Another potential limitation is the observational nature of the study, which precludes the analysis of causality of the detected associations. Still, many of our findings itself, and the direction of causality, are supported by results from in vivo animal studies.

Together, our analyses indicate that the commonly prescribed AEDs carbamazepine and valproate affect serum Se and $\mathrm{Cu}$ levels. Furthermore, while Se levels may partially affect $\mathrm{TH}$ signaling via modifying the expression of deiodinases, the effects of $\mathrm{Cu}$ on thyroid parameters may be primarily driven by its effects on TBG. Future research is needed to explore the underlying mechanisms of the observed associations in the current study and to investigate to what extent trace elements are risk factors for the development of thyroid diseases.

\section{Supplementary data}

This is linked to the online version of the paper at http://dx.doi.org/10.1530/ EJE-15-1081.

\section{Declaration of interest}

The authors declare that there is no conflict of interest that could be perceived as prejudicing the impartiality of the research reported.

\section{Funding}

W E Visser is supported by an Erasmus University Fellowship. L Schomburg received support from the Deutsche Forschungsgemeinschaft DFG (Scho 849/4-1). A Schuette received a PhD stipend from the BerlinBrandenburg School for Regenerative Therapies (BSRT).

\section{References}

1 Oppenheimer JH. Evolving concepts of thyroid hormone action. Biochimie 199981 539-543. (doi:10.1016/S0300-9084(99)80107-2)

2 Bianco AC \& Kim BW. Deiodinases: implications of the local control of thyroid hormone action. Journal of Clinical Investigation $2006 \mathbf{1 1 6}$ 2571-2579. (doi:10.1172/JCI29812)

3 Yen PM. Physiological and molecular basis of thyroid hormone action. Physiological Reviews 200181 1097-1142.

4 Golden SH, Robinson KA, Saldanha I, Anton B \& Ladenson PW. Clinical Review: Prevalence and incidence of endocrine and metabolic disorders in the United States: a comprehensive review. Journal of Clinical Endocrinology and Metabolism 200994 1853-1878. (doi:10.1210/jc. 2008-2291)
5 Pearce EN. Thyroid dysfunction in perimenopausal and postmenopausal women. Menopause International 2007 13 8-13.

6 Peeters RP. Thyroid hormones and aging. Hormones $2008728-35$. (doi:10.14310/horm.2002.1111035)

7 Copius Peereboom JW. General aspects of trace elements and health. Science of the Total Environment 198542 1-27. (doi:10.1016/ 0048-9697(85)90003-8)

8 Bernal J. Thyroid hormones and brain development. Vitamins and Hormones 200571 95-122.

9 Friesema EC, Grueters A, Biebermann H, Krude H, von Moers A, Reeser M, Barrett TG, Mancilla EE, Svensson J, Kester MH et al. Association between mutations in a thyroid hormone transporter and severe X-linked psychomotor retardation. Lancet 2004364 1435-1437. (doi:10.1016/S0140-6736(04)17226-7)

10 Dumitrescu AM, Liao XH, Best TB, Brockmann K \& Refetoff S. A novel syndrome combining thyroid and neurological abnormalities is associated with mutations in a monocarboxylate transporter gene. American Journal of Human Genetics 200474 168-175. (doi:10.1086/ 380999)

11 Bochukova E, Schoenmakers N, Agostini M, Schoenmakers E, Rajanayagam O, Keogh JM, Henning E, Reinemund J, Gevers E, Sarri $\mathrm{M}$ et al. A mutation in the thyroid hormone receptor $\alpha$ gene. New England Journal of Medicine 2012366 243-249. (doi:10.1056/ NEJMoa1110296)

12 van Mullem A, van Heerebeek R, Chrysis D, Visser E, Medici M, Andrikoula M, Tsatsoulis A, Peeters R \& Visser TJ. Clinical phenotype and mutant TR $\alpha 1$. New England Journal of Medicine 2012366 1451-1453. (doi:10.1056/NEJMc1113940)

13 van Mullem AA, Chrysis D, Eythimiadou A, Chroni E, Tsatsoulis A, de Rijke YB, Visser WE, Visser TJ \& Peeters RP. Clinical phenotype of a new type of thyroid hormone resistance caused by a mutation of the TR $\alpha 1$ receptor: consequences of LT4 treatment. Journal of Clinical Endocrinology and Metabolism 201398 3029-3038. (doi:10.1210/jc. 2013-1050)

14 Moran C, Schoenmakers N, Agostini M, Schoenmakers E, Offiah A, Kydd A, Kahaly G, Mohr-Kahaly S, Rajanayagam O, Lyons G et al. An adult female with resistance to thyroid hormone mediated by defective thyroid hormone receptor $\alpha$. Journal of Clinical Endocrinology and Metabolism 201398 4254-4261. (doi:10.1210/jc. 2013-2215)

15 Scheiber IF, Mercer JF \& Dringen R. Metabolism and functions of copper in brain. Progress in Neurobiology 2014116 33-57. (doi:10.1016/ j.pneurobio.2014.01.002)

16 Bastian TW, Prohaska JR, Georgieff MK \& Anderson GW. Perinatal iron and copper deficiencies alter neonatal rat circulating and brain thyroid hormone concentrations. Endocrinology 2010151 4055-4065. (doi:10.1210/en.2010-0252)

17 Savaskan NE, Brauer AU, Kuhbacher M, Eyupoglu IY, Kyriakopoulos A, Ninnemann O, Behne D \& Nitsch R. Selenium deficiency increases susceptibility to glutamate-induced excitotoxicity. FASEB Journal 2003 17 112-114.

18 Schweizer U, Brauer AU, Kohrle J, Nitsch R \& Savaskan NE. Selenium and brain function: a poorly recognized liaison. Brain Research. Brain Research Reviews 200445 164-178. (doi:10.1016/j.brainresrev. 2004.03.004)

19 Zimmermann MB \& Kohrle J. The impact of iron and selenium deficiencies on iodine and thyroid metabolism: biochemistry and relevance to public health. Thyroid 200212 867-878. (doi:10.1089/ 105072502761016494)

20 Jain RB. Thyroid function and serum copper, selenium, and zinc in general US population. Biological Trace Element Research 2014159 87-98. (doi:10.1007/s12011-014-9992-9)

21 Bastian TW, Anderson JA, Fretham SJ, Prohaska JR, Georgieff MK \& Anderson GW. Fetal and neonatal iron deficiency reduces thyroid hormone-responsive gene mRNA levels in the neonatal rat 
hippocampus and cerebral cortex. Endocrinology 2012153 5668-5680. (doi:10.1210/en.2012-1067)

22 Bastian TW, Prohaska JR, Georgieff MK \& Anderson GW. Fetal and neonatal iron deficiency exacerbates mild thyroid hormone insufficiency effects on male thyroid hormone levels and brain thyroid hormone-responsive gene expression. Endocrinology 2014155 1157-1167. (doi:10.1210/en.2013-1571)

23 Visser WE, de Rijke YB, van Toor H \& Visser TJ. Thyroid status in a large cohort of patients with mental retardation: the TOP-R (Thyroid Origin of Psychomotor Retardation) study. Clinical Endocrinology 2011 75 395-401. (doi:10.1111/j.1365-2265.2011.04089.x)

24 Liewendahl K, Majuri H \& Helenius T. Thyroid function tests in patients on long-term treatment with various anticonvulsant drugs. Clinical Endocrinology 19788 185-191. (doi:10.1111/j.1365-2265.1978. tb01493.x)

25 Verrotti A, Laus M, Scardapane A, Franzoni E \& Chiarelli F. Thyroid hormones in children with epilepsy during long-term administration of carbamazepine and valproate. European Journal of Endocrinology/ European Federation of Endocrine Societies 2009160 81-86. (doi:10.1530/ EJE-08-0325)

26 Lossius MI, Tauboll E, Mowinckel P \& Gjerstad L. Reversible effects of antiepileptic drugs on thyroid hormones in men and women with epilepsy: a prospective randomized double-blind withdrawal study. Epilepsy \& Behavior 2009 16 64-68. (doi:10.1016/j.yebeh.2009.07.014)

27 Surks MI \& DeFesi CR. Normal serum free thyroid hormone concentrations in patients treated with phenytoin or carbamazepine. A paradox resolved. Journal of the American Medical Association 1996275 1495-1498. (doi:10.1001/jama.1996.03530430039036)

28 Liewendahl K, Helenius T, Majuri H, Ebeling P \& Ahlfors UG. Effect of anticonvulsant and antidepressant drugs on iodothyronines in serum. Scandinavian Journal of Clinical and Laboratory Investigation 198040 767-774. (doi:10.3109/00365518009095594)

29 Doneray H, Kara IS, Karakoc A, Tan H \& Orbak Z. Serum thyroid hormone profile and trace elements in children receiving valproic acid therapy: a longitudinal and controlled study. Journal of Trace Elements in Medicine and Biology 201226 243-247. (doi:10.1016/j.jtemb. 2012.03.001)

30 Kaji M, Ito M, Okuno T, Momoi T, Sasaki H, Yamanaka C, Yorifuji T \& Mikawa H. Serum copper and zinc levels in epileptic children with valproate treatment. Epilepsia 199233 555-557. (doi:10.1111/ j.1528-1157.1992.tb01709.x)

31 Karikas GA, Schulpis KH, Bartzeliotou A, Karakonstantakis T, Georgala S, Kanavaki I, Demetriou E \& Papassotiriou I. Lipids, lipoproteins, apolipoproteins, selected trace elements and minerals in the serum of children on valproic acid monotherapy. Basic \& Clinical Pharmacology \& Toxicology 200698 599-603. (doi:10.1111/j.1742-7843. 2006.pto_402.x)

32 Kurekci AE, Alpay F, Tanindi S, Gokcay E, Ozcan O, Akin R, Isimer A \& Sayal A. Plasma trace element, plasma glutathione peroxidase, and superoxide dismutase levels in epileptic children receiving antiepileptic drug therapy. Epilepsia 199536 600-604. (doi:10.1111/j.1528-1157. 1995.tb02574.x)

33 Armutcu F, Ozerol E, Gurel A, Kanter M, Vural H, Yakinci C \& Akyol O. Effect of long-term therapy with sodium valproate on nail and serum trace element status in epileptic children. Biological Trace Element Research 2004102 1-10. (doi:10.1385/BTER:102:1-3:001)

34 Hoeflich J, Hollenbach B, Behrends T, Hoeg A, Stosnach H \& Schomburg L. The choice of biomarkers determines the selenium status in young German vegans and vegetarians. British Journal of Nutrition 2010104 1601-1604. (doi:10.1017/S0007114510002618)

35 Sarangi SC, Tripathi M, Kakkar AK \& Gupta YK. Effect of antiepileptic therapy on trace elements status in Indian population in a tertiary care hospital from northern India: a cross sectional study. Epilepsy Research 2014108 917-927. (doi:10.1016/j.eplepsyres.2014.01.014)

36 Hamed SA, Abdellah MM \& El-Melegy N. Blood levels of trace elements, electrolytes, and oxidative stress/antioxidant systems in epileptic patients. Journal of Pharmacological Sciences 200496 465-473. (doi:10.1254/jphs.FPJ04032X)

37 Verrotti A, Basciani F, Trotta D, Pomilio MP, Morgese G \& Chiarelli F. Serum copper, zinc, selenium, glutathione peroxidase and superoxide dismutase levels in epileptic children before and after 1 year of sodium valproate and carbamazepine therapy. Epilepsy Research 200248 71-75. (doi:10.1016/S0920-1211(01)00322-9)

38 Combs GF Jr. Selenium in global food systems. British Journal of Nutrition 200185 517-547. (doi:10.1079/BJN2000280)

$39 \mathrm{Lu} \mathrm{J} \&$ Holmgren A. Selenoproteins. Journal of Biological Chemistry 2009 284 723-727. (doi:10.1074/jbc.R800045200)

40 Kohrle J \& Gartner R. Selenium and thyroid. Best Practice \& Research. Clinical Endocrinology \& Metabolism 200923 815-827. (doi:10.1016/ j.beem.2009.08.002)

41 Drutel A, Archambeaud F \& Caron P. Selenium and the thyroid gland: more good news for clinicians. Clinical Endocrinology 201378 155-164. (doi:10.1111/cen.12066)

42 Schomburg L \& Kohrle J. On the importance of selenium and iodine metabolism for thyroid hormone biosynthesis and human health. Molecular Nutrition \& Food Research 200852 1235-1246. (doi:10.1002/ mnfr.200700465)

43 Kohrle J, Jakob F, Contempre B \& Dumont JE. Selenium, the thyroid, and the endocrine system. Endocrine Reviews $200526944-984$. (doi:10.1210/er.2001-0034)

44 Schmutzler C, Mentrup B, Schomburg L, Hoang-Vu C, Herzog V \& Kohrle J. Selenoproteins of the thyroid gland: expression, localization and possible function of glutathione peroxidase 3. Biological Chemistry 2007388 1053-1059. (doi:10.1515/BC.2007.122)

45 Vanderpas JB, Contempre B, Duale NL, Goossens W, Bebe N, Thorpe R, Ntambue K, Dumont J, Thilly CH \& Diplock AT. Iodine and selenium deficiency associated with cretinism in northern Zaire. American Journal of Clinical Nutrition 199052 1087-1093.

46 Beckett GJ, MacDougall DA, Nicol F \& Arthur R. Inhibition of type I and type II iodothyronine deiodinase activity in rat liver, kidney and brain produced by selenium deficiency. Biochemical Journal 1989259 887-892. (doi:10.1042/bj2590887)

47 Bermano G, Nicol F, Dyer JA, Sunde RA, Beckett GJ, Arthur JR \& Hesketh JE. Tissue-specific regulation of selenoenzyme gene expression during selenium deficiency in rats. Biochemical Journal $1995 \mathbf{3 1 1}$ 425-430. (doi:10.1042/bj3110425)

48 DePalo D, Kinlaw WB, Zhao C, Engelberg-Kulka H \& St Germain DL. Effect of selenium deficiency on type I 5'-deiodinase. Journal of Biological Chemistry 1994269 16223-16228.

49 Chanoine JP, Safran M, Farwell AP, Tranter P, Ekenbarger DM, Dubord S, Alex S, Arthur JR, Beckett GJ, Braverman LE et al. Selenium deficiency and type II 5'-deiodinase regulation in the euthyroid and hypothyroid rat: evidence of a direct effect of thyroxine. Endocrinology 1992131 479-484.

50 Meinhold H, Campos-Barros A, Walzog B, Kohler R, Muller F \& Behne D. Effects of selenium and iodine deficiency on type I, type II and type III iodothyronine deiodinases and circulating thyroid hormones in the rat. Experimental and Clinical Endocrinology 1993101 87-93. (doi:10.1055/s-0029-1211212)

51 Hess SY. The impact of common micronutrient deficiencies on iodine and thyroid metabolism: the evidence from human studies. Best Practice \& Research. Clinical Endocrinology \& Metabolism 201024 117-132. (doi:10.1016/j.beem.2009.08.012)

52 Schomburg L \& Schweizer U. Hierarchical regulation of selenoprotein expression and sex-specific effects of selenium. Biochimica et Biophysica Acta 20091790 1453-1462. (doi:10.1016/ j.bbagen.2009.03.015)

53 Alturfan AA, Zengin E, Dariyerli N, Alturfan EE, Gumustas MK, Aytac E, Aslan M, Balkis N, Aksu A, Yigit G et al. Investigation of zinc and copper levels in methimazole-induced hypothyroidism: relation with the oxidant-antioxidant status. Folia Biologica 200753 183-188. 
54 Mittag J, Behrends T, Nordstrom K, Anselmo J, Vennstrom B \& Schomburg L. Serum copper as a novel biomarker for resistance to thyroid hormone. Biochemical Journal 2012443 103-109. (doi:10.1042/ BJ20111817)

55 Tahboub R \& Arafah BM. Sex steroids and the thyroid. Best Practice \& Research. Clinical Endocrinology \& Metabolism 200923 769-780. (doi:10.1016/j.beem.2009.06.005)

56 Surks MI \& Sievert R. Drugs and thyroid function. New England Journal of Medicine 1995333 1688-1694. (doi:10.1056/ NEJM199512213332507)

57 Sobbrio GA, Granata A, Granese D, D'Arrigo F, Panacea A, Nicita R, Pulle C \& Trimarchi F. Sex hormone binding globulin, cortisol binding globulin, thyroxine binding globulin, ceruloplasmin: changes in treatment with two oral contraceptives low in oestrogen. Clinical and Experimental Obstetrics \& Gynecology 199118 43-45.
58 Buchwald A. Serum copper elevation from estrogen effect, masquerading as fungicide toxicity. Journal of Medical Toxicology 20084 30-32. (doi:10.1007/BF03160948)

59 Arredondo M, Nunez H, Lopez G, Pizarro F, Ayala M \& Araya M. Influence of estrogens on copper indicators: in vivo and in vitro studies. Biological Trace Element Research 2010134 252-264. (doi:10.1007/ s12011-009-8475-x)

60 Hinks LJ, Clayton BE \& Lloyd RS. Zinc and copper concentrations in leucocytes and erythrocytes in healthy adults and the effect of oral contraceptives. Journal of Clinical Pathology 198336 1016-1021. (doi:10.1136/jcp.36.9.1016)

61 Raymunt J \& Russ EM. Influence of estrogens on total serum copper and caeruloplasmin. Proceedings of the Society for Experimental Biology and Medicine 195692 465-466. (doi:10.3181/00379727-9222512)

Received 4 November 2015

Revised version received 17 December 2015

Accepted 23 December 2015 